\title{
THE EFFECTIVENESS AND RELEVANCE OF SOCIAL SECURITY ALLOWANCE IN NEPAL
}

\author{
Indra Malakar*
}

\begin{abstract}
This study attempts to analyze the effectiveness and relevance of Social Security Allowance (SSA) among the beneficiaries of Kirtipur Municipality 7, Kathmandu district. This study is based on primary data collection in terms of use of the allowance, sufficiency or insufficiency of the distributed amount and use of it to maintain the social status. The problems associated with the respondents along with the program were also purposively selected to verify the objectives. This study reveals that social security allowance have been used for the fulfilment of recipients basic personal needs. The effectiveness of this allow ace is highly appreciable.
\end{abstract}

Key words: Needs, sufficiency, insufficiency, allowance.

\section{INTRODUCTION}

Today's society is facing a situation which has never been known before along with the increasing insecurities of life. Therefore, to safeguard the individual and the society for these uncertainties and insecurities there is in need of social security. "The state shall make itself responsible for ensuring a minimum standard of material welfare to its entire citizen on a basis wide enough to cover all contingencies of life from womb to the tomb (ILO, 1942).

Similarly, everyday in our daily life we come across the incidents on social insecurity related events including abductions, killings, accidents, child labour, exploitation, violence against women, misbehaviours to senior citizens and many more. Obviously all these incidents demand state security since it is the state's responsibility to ensure the right to life to every citizen with dignity, justice and equality. Therefore, social security service is a tool for government to take care of well being of its citizens. Lack of updated information, lack of citizenship certificate, use of ghost names, fruitfulness of program, determining how much the target groups are actually benefitting is still a challenge. Purposes of using allowance, to what extent they are satisfied to use it, changing life style of beneficiaries,

* Mr. Malakar is a Lecturer, Patan Campus, Patandhoka, TU. 
increasing or decreasing of love and affection and so on are some of the key issues associated with the effective implementation of the social security program in the country as not found in the practice yet. Thus, these arguments of social security system are still needed to be brought forward and to be addressed properly. And this study can equally be significant for those researches or policy makers attempting to answer or change policy making in order to increase certain level of satisfaction of these people regarding the benefits they have received.

\section{OBJECTIVES}

The overall objective of this study is to analyze the effectiveness of Social Security Allowance among the beneficiaries of Kirtipur Municipality 7. The specific objectives are as follows:

i) To analyze effectiveness of the allowance in terms of use of allowance, sufficiency of the distributed amount and use of allowance to maintain social status.

ii) To analyze the problems associated with the respondents and program in relation to its effectiveness.

\section{METHODOLOGY}

This study was based on ward number 7 of Kirtipur Municipality. Only four categories were considered and others were not applicable in this study. The study has included total (117) beneficiaries as informants from the aforementioned four categories. The study used simple statistical tools such as frequency distribution, percent, average, rate etc. The study area was ward number 18 before local election but now it is ward number 7 . None of the wards have been merged for forming ward number 7. And this is the study area which has been selected purposively. According to census 2011 A.D., total population of this ward was 4661 with male population 2934 and female population 1727 . The exploratory and descriptive research design alone with both qualitative and quantitative data was used in this study. Of the total beneficiaries 117 of the fiscal year 2073/74, 8 samples were deducted due to death of respondents or from different ward and 109 samples were taken including 47 senior citizens, 54 widowed, 5 completely disabled, 2 partially disabled and 1 single woman who were receiving Social Security Allowance were regarded as the universe and sample of the study and this data was available and collected from Kirtipur Municipality where all the records of qualified beneficiaries are found. This universe was 
selected as the sample population and census method was applied for the data collection for the concerned.

For data collection respondents were given questions to those who could read and write and to those who could not read and write were asked to answer the questions and filled up questionnaire were collected, edited errors, separated variables into different codes and then were carefully entered then transcribed into English and analyzed.

The research was designed to collect case studies of those beneficiaries with typical and glaring cases for qualitative data to provide strength to the findings and participants were not kept vulnerable to any risk during the study with pre informed verbal or written consent to ensure the privacy of all the participants.

\section{RESULT AND DISCUSSION}

The Government of Nepal has been implementing various social security programs for decades. In case of Nepal, the government provides non-contributory pension, provident fund, limited care facilities, maternity leave and work injury as well as accident compensation for the employees. Provident fund is the main security component in Nepal (NPC, 2012).

The United Nation celebrated the year 1999 as the "International Year Of Older Person," and raised a slogan as "Towards A Society for all Ages" and currently October 1 every year is celebrated as the day for the older persons. The Madrid International plan of Action on Ageing 2002 passed by the second World Assembly on Ageing, Madrid, 8-12 April 2002 has raised popular slogan as "Towards a society for all Ages" and identified three priority direction and eighteen main concern sectors to promote and protect the human rights of the senior citizens.

The social security allowance was nearly 11 billion in the fiscal year 2013/14 out of the total budget around 518 billion. Moreover, SSA went on increasing in each fiscal year and tripled during the fiscal year 2016/17. In the fiscal year 2017/18 this social security allowance was around 40 billion. This trend shows in each fiscal year the budget for social security allowance being increasing and creating pressure to spend on non contributory pension. The aging population is increasing on one hand and beneficiaries are also increasing on the other hand due to the various categories defined by the government of Nepal. In this situation the pressure on budget is higher to 
cope with such challenges. This can lead to retard the development process (Table 1).

Table 1: Annual Total Budget and Budget for Social Security Allowance (SSA)

\begin{tabular}{|r|r|r|}
\hline \multicolumn{1}{|c|}{ Fiscal Year } & \multicolumn{1}{|c|}{$\begin{array}{c}\text { Total Budget } \\
\text { (Rs. In Billions) }\end{array}$} & $\begin{array}{c}\text { SSA } \\
\text { (Rs. In Billions) }\end{array}$ \\
\hline $2013 / 14$ & 517.24 & 10.37 \\
\hline $2014 / 15$ & 618.10 & 12.73 \\
\hline $2015 / 16$ & 819.47 & 16.45 \\
\hline $2016 / 17$ & 1048.92 & 32.70 \\
\hline $2017 / 18$ & 1278.99 & 39.26 \\
\hline
\end{tabular}

Source: Red book, MOF, 2018.

\section{Situation, Operational Modality and Goal of Social Security in Nepal}

In the fiscal year 1994/95, the government of Nepal has introduced the Social Security Program as a part of its social security arrangement which is a non contributory benefit of an income maintenance type of social security program in which the government provides cash transfers to eligible beneficiaries. The scheme covers disabled, widows, endangered races and elderly people who have completed 75 years of age in general which was later revised to 60 plus in the case of senior citizens (Dalit) and 70 plus for others. Similarly, the people living in the Karnali zone's age threshold was fixed at 60 considering the longevity (Singh, 2013).

In Nepal, various ages are taken for multiple purposes. The Government has been giving some elderly facilities to those above 75 years from fiscal year 2052/53BS. The civil services act $2049 \mathrm{BS}$, has facilitated the civil servants to work till the age of fifty eight. The chief justices or any other judge of the Supreme Court will hold office until he attains the age of sixty five. Similarly, the Chief Judge and other Judges of an Appellate or District Court continue in the office till the age of sixty-five. Similarly, the Chief Judge and the other Judges of the Appellate court or District court remain in the office till the age sixty-three (GON, 2001).

With the notion of expanding the social security right of citizens and to honouring it, the Social security Program Operation Procedure 2065 has been formulated and implemented under the Local Self-Governance Act 2055, Section 236(2) stating the objectives as defining target group, 
ease of allowance distribution, maintaining and updating information flow and information flow system, maintaining transparency and monitoring effectively. The three categories under this modality are: those completing 70 years; those over 60 years (Karnali areas) and above 60 years (Dalits), endangered races as stated by the state (Endangered races are Kusunda, Bankariya, Raute, Surel, Hayu, Raji, Kishan, Lepche, Meche, Kusawadiya) , single woman such as widow, single unmarried and divorced woman. Disable one such as fully disabled and partially disabled as defined by the state. Proof to Determining Eligibility requires citizenship, identity card is valid only from forthcoming year, last date of month will be taken if date is not mentioned and last month of the year will be taken if only year is mentioned and final decision on age will be taken by the District Administration Office if there is controversy. Rural and Urban municipalities must notify the candidates to renew their ID cards within the first week of Marg. Eligible candidates must produce two passport size photographs and citizenship card for their ID card and an application must be submitted in standard format for renewal. VDCs and municipalities must facilitate those beneficiaries belonging to the endangered race in getting their ID card (NPC, 2012).

Social security is a fundamental human right to which every individual has been entitled as a member of the society. Its main objective is to give individual that make confidence through which they must be sure that their level of living and quality of life will be adversely affected due to any mishaps and contingencies. Similarly, the aim of social security has been widened to include the complete quality of working and living life in each aspect. Moreover, it is a wise investment which motives the employees and boosts their morale leaving to higher quality production and it is a basic instrument of social and economic justice among members of the society. Furthermore, it leads to adoption of the schemes of unemployment, insurance and creation of new employment through a drive for rational planning and industrial development, establishes a scheme of old age and unemployment pension, covers more different types of risks like sickness, maturity and employment injuries. In addition, it also emphasizes and ensures that the ideas of human dignity and social justice are duty taken care (Joshi, 2010).

The traditional values of providing care and support for senior members have been dominated by changing needs of families that pressure them live independently. In many cases, older family members are left behind.Though the allowances have been distributed to the beneficiaries of 
the Kirtipur Municipality, it is still unclear about the impact and effectiveness brought about by the benefits (K.M, 2074). Actually what kind of role has been played by the benefits? Or policies need to be changed are still burning issues in the context of this region. The demographic and Socio-economic characteristics of the respondents was seemed to be as follows:

Table 2: Demographic and Socio-Economic Characteristics of Respondents

\begin{tabular}{|l|r|r|r|r|r|r|}
\hline \multirow{2}{*}{ Category } & \multicolumn{2}{|c|}{ Male } & \multicolumn{2}{c|}{ Female } & \multicolumn{2}{c|}{ Total } \\
\cline { 2 - 8 } & No. & Percent & No. & Percent & No. & Percent \\
\hline Senior citizen & 21 & 77.8 & 26 & 31.7 & 47 & 43.1 \\
\hline Widowed & 0 & .0 & 54 & 65.9 & 54 & 49.5 \\
\hline Completely disabled & 4 & 14.8 & 1 & 1.2 & 5 & 4.6 \\
\hline Partially disabled & 2 & 7.4 & 0 & .0 & 2 & 1.8 \\
\hline Single women & 0 & .0 & 1 & 1.2 & 1 & 0.9 \\
\hline \multirow{2}{*}{ Present Job } & \multicolumn{2}{|c|}{ Male } & \multicolumn{2}{|c|}{ Female } & \multicolumn{2}{|c|}{ Total } \\
\cline { 2 - 8 } & No. & percent & No. & percent & No. & Percent \\
\hline Yes & 2 & 7.4 & 17 & 20.7 & 19 & 17.4 \\
\hline No & 25 & 92.6 & 65 & 79.3 & 90 & 82.6 \\
\hline Total & 27 & 100.0 & 82 & 100.0 & 109 & 100.0 \\
\hline
\end{tabular}

Source: Field survey, 2017.

Note: "Women who were over 60 years of age without marriage or divorced.

Of the total 109 respondents, above two-fifths (43.1\%) of the beneficiaries received allowance as senior citizen. This is nearly one half $(49.5 \%)$ of widowed, below one-tenths $(4.6 \%)$ of completely disabled and few $(4.6 \%)$ of partially disabled and very few $(1.8 \%)$ of single women. Out of the 27 male, above three-fourths (77.8\%) Senior citizen, above onetenths $(14.8 \%)$ completely and below one-tenths (7.4\%) partially disabled respondents received allowance by category. The data revealed the highest proportion of Senior citizen in the male and widowed in the female and with least proportion of partially disabled in the male and completely disabled in the female receiving allowance by category (Table 2).

Moreover, below one-fifths had job currently whereas most of the respondents (82.6\%) did not have job. Among them very few male respondent 
(7.4\%) had job currently but majority of male respondents (92.6\%) did not have job. In case of female, this was one-fifths (20.7\%) and nearly three-fifths (79.3\%) having job currently and without job respectively. By proportion nearly one-third male $(7.4 \%)$ than female $(20.7 \%)$ had job whereas more male (92.6\%) than female (79.3\%) were without job (Table 3).

\section{Effectiveness Of Social Security Allowance}

The effectiveness of social security allowances was found to be as follows:

Table 3: Distribution of Respondents by Usages and According to Background Characterise

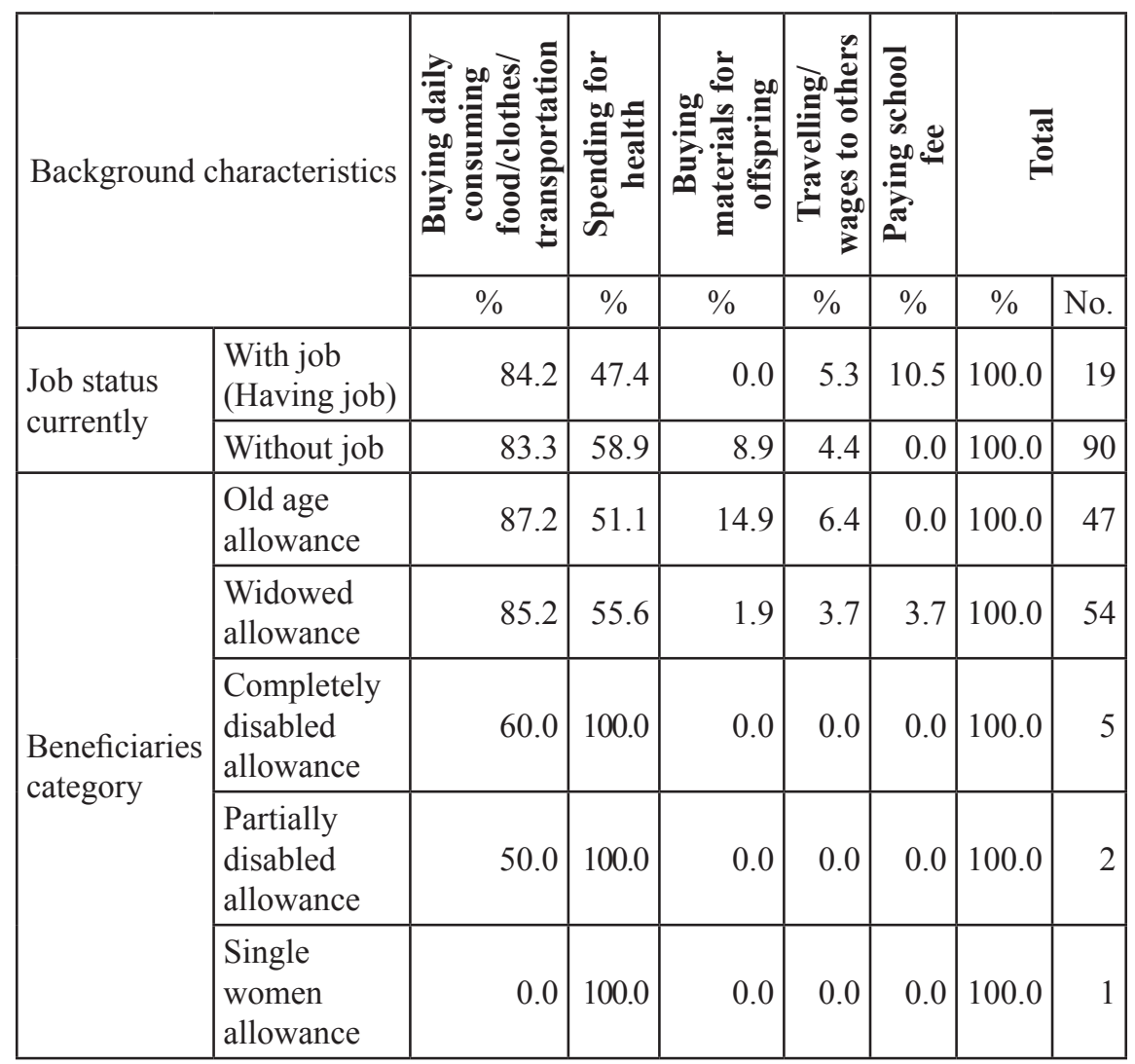

Source: Field survey, 2017.

By current job status, out of the 19 job holders above fourfifths (84.4\%) used allowance for buying daily consuming food/clothes/ transportation and few job holders $(5.3 \%)$ used allowance for travelling/ 
wages to others sharing the highest and lowest proportion where as this was more than three-fifths $(83.3 \%)$ and few $(4.4 \%)$ without job beneficiaries sharing the highest and lowest proportion (Table 3 ). By beneficiary category, most of the beneficiaries in the beneficiary category used allowance for buying daily consuming food/clothes/transportation where as overall all completely disabled, partially disabled and single women used allowance for health treatment.

Table 4: Distribution of Beneficiaries by Sufficiency and Insufficiency of Allowance

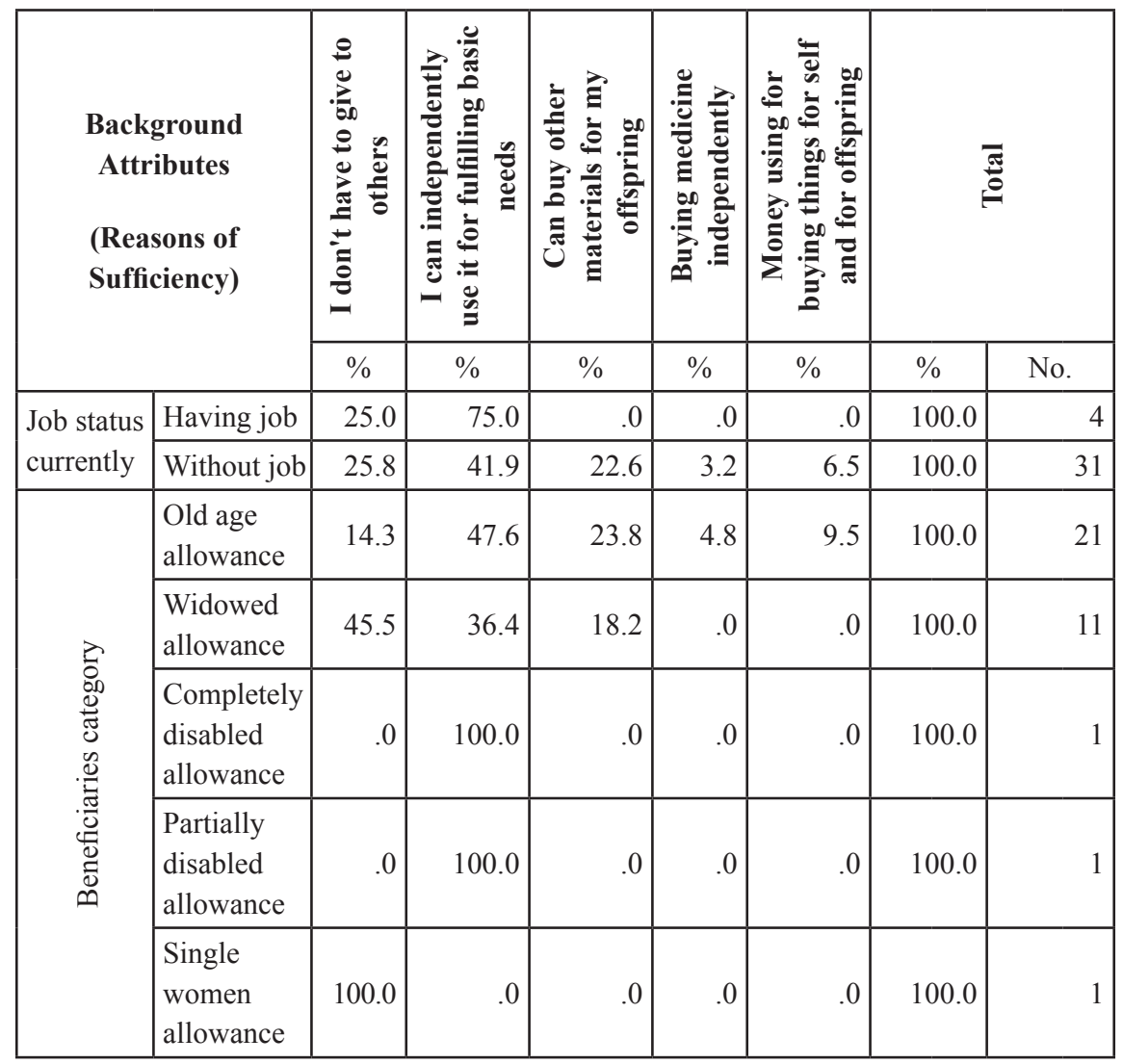

\section{Contd.}




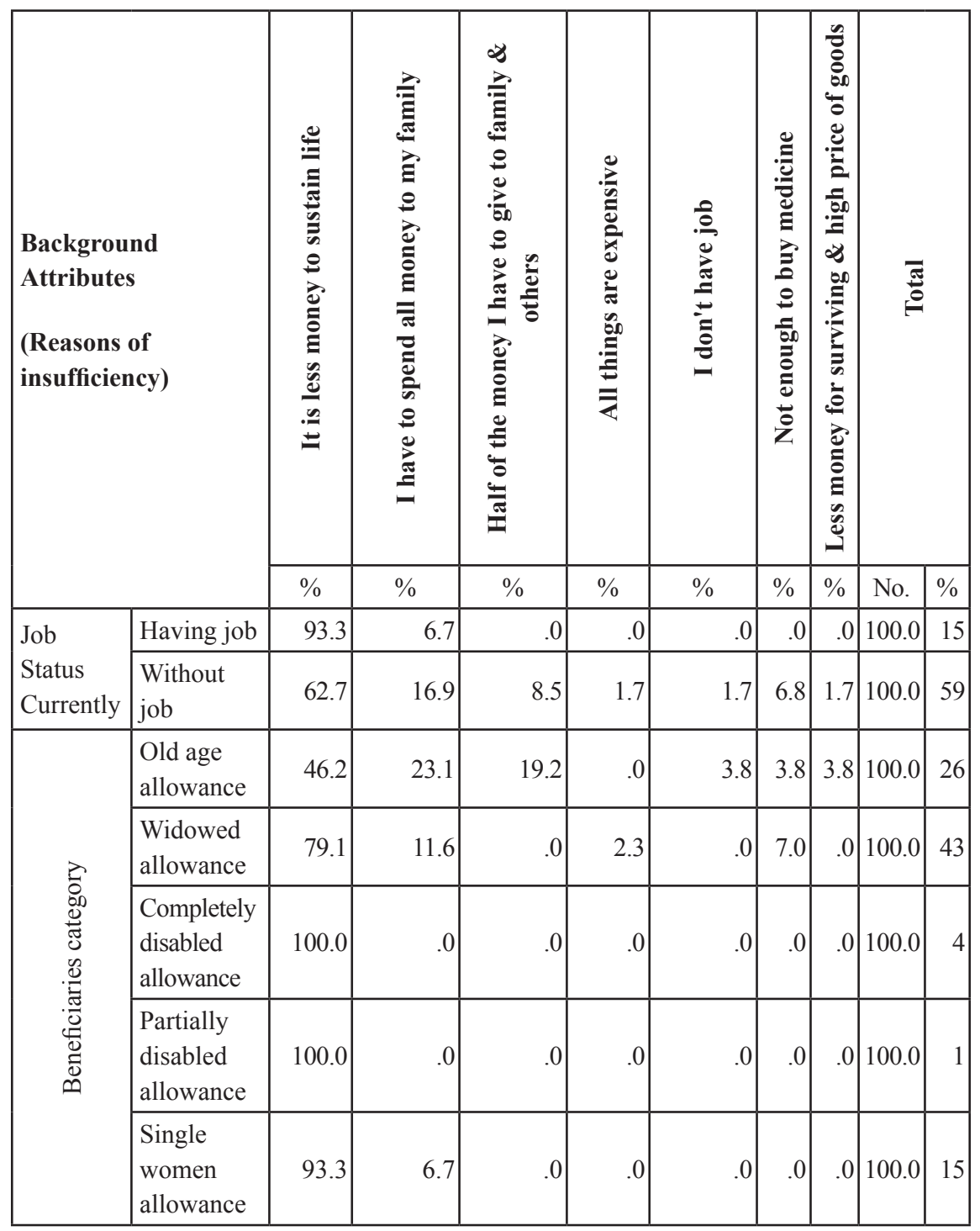

Source: Field survey, 2017.

Sufficiency: By job status, one-fifth (25\%) and three-fifths (75\%) respondents having jobs reported sufficient of allowance as "I don't have to give to others" and "I can independently use it for fulfilling basic needs". In case of jobless respondents, two-fifths (41.9\%) and very few (3.2\%) respondents shared the highest and least proportion reporting sufficient as "I can independently use it for fulfilling basic needs" and "buying medicine independently" respectively. Moreover, above two-fifths (45.5\%) widowed, 
100 percent completely and partially disabled, nearly one-fourths $(23.8 \%)$ old aged, very little (4.8\%) old aged and again nearly one-tenth $(9.5 \%)$ old aged shared the highest proportion and above one-tenth (14.3\%) old aged, nearly two-fifths $(36.4 \%)$ completely disabled, nearly one-fifths $(18.2 \%)$ widowed and none of the beneficiaries except old age shared the least proportion reporting sufficiency of allowance as "I don't have to give to others', "I can independently use it for fulfilling basic needs", "can buy materials for my offspring", "buying medicine independently" and "money using for buying things for self and offspring respectively (Table 4).

Table 5: Distribution of Respondents by Distance of Allowance Dispatching and Time Duration of Waiting

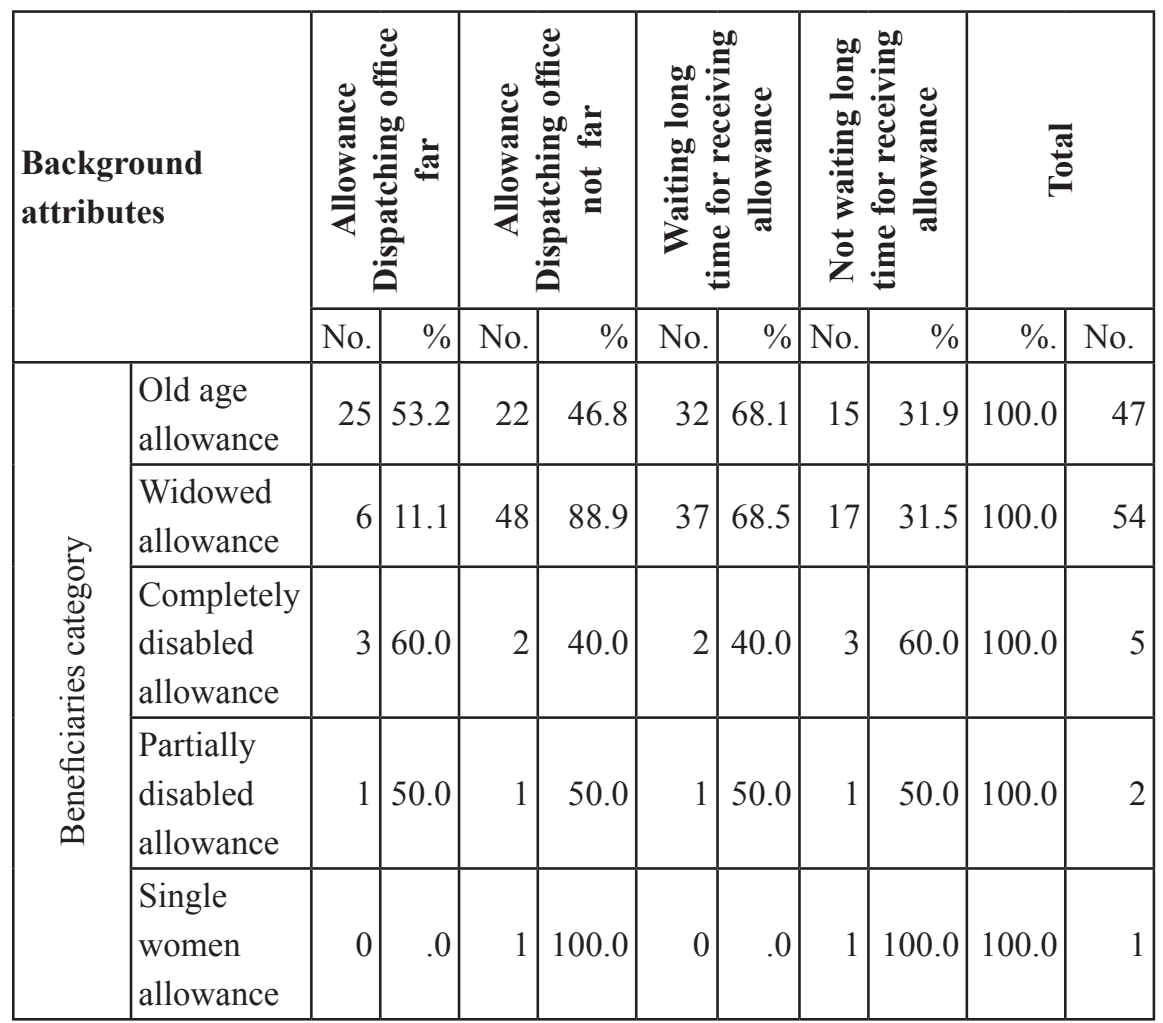

Source: Field survey, 2017.

By proportion three-fifths $(60 \%)$ completely disabled and more than half (53.2\%) completely disabled reported that allowance dispatch far from their home where as above three-fifths $(68.1 \%)$ senior citizen and twofifths $(20 \%)$ completely disabled reported waiting longer period of time 
to receive allowance. Just above one-tenth (11.1\%) widowed reported far distant of allowance dispatching office however majority of them reported they have to wait longer period of time for it.

In one of the cases, the women aged 81, said, she has three sons. Now she is living with middle son but she is suffering from depression, pressure and other diseases. The property retained in the name of the women for livelihood (Juine) was sold by their sons and they shared the money between them. When woman went to live with elder son, he said his family was going to America so nobody would be in the home and no one would remain to look after her. Woman went to live with youngest son when elder son denied keeping her in his house. Youngest son also said to her mother (woman) that he had no room for her. Mother or woman wanted to live with elder or younger son because middle son had intercaste marriage and woman did not like to live with middle son. At last when both the youngest and elder son denied looking their mother, the women is living with middle son. This entire scenario made her depression. The comparative situation was also spelled out in this study as follows:

The study of Social Security/ Social Protection In Nepal Situational Analysis in 2012 by Dilli Raj Khanal analyzed the comprehensive profile of social security/social protection in Nepal's formal and informal economies emphasizing to workers and families in the informal economy (Khanal, 2012). The study of The Effectiveness of Social Security Allowance Program in 2015 by Suman Kharel which is a mini research report of Ilam district was related to only four categories of beneficiary viz senior citizen (Dalit and non dalit), endangered race (Lepcha) and single women. And it explores on the distributional aspects (usages) of social security allowance but not with whether they are satisfied with the distributed amount with different reasons (Kharel, 2015). The study of Assessment of Social Security Allowance Program carried out by National Planning Commission in 2012 in Nepal is very close to this study; however this study analyzed the usages, sufficiency and insufficiency of allowance but not with the reasons of why sufficient? or why insufficient?(NPC,2012).

In the fiscal year 1994/95, the government of Nepal has introduced the Social Security Program as a part of its social security arrangement. This scheme covers disabled, widows aged 60 plus, endangered races and elderly people who have completed 75 years of age in general which was later revised to 60 plus in the case of senior citizens (Dalit) and 70 plus 
for others. Similarly, the people living in the Karnali zone's age threshold was fixed at 60 considering the longevity (Singh, 2013). In the U.S Social Security System, individuals are entitled to claim benefits as early as age 62 but they can also differ the age at which they claim to as late age 70 . Eligibility participants of social security system have the ability to claim benefits being actuarially adjusted based on date of claiming (Brown, Mitcheel \& Kapteyn, 2010). In Canada if a person is a low income senior, the person may be eligible for other benefits as early as age 60 but the person most apply to receive old age security benefits In Hongkong, monthly benefits amount to HK\$ 675 for those aged 70 and HK\$ 595 for those aged 65-69 (USSSA, 2006). The result of earlier research and empirical evidence show that social cash transfer can be feasible even in Low Countries if well designed and adapted like in Senegal and Tanzania in Africa (Tostensen, 2004). Therefore, there can be the good discussion about the age thresh hold such as on which basis the age for social security should be taken either on the basis of longevity or depending on national budget and so on.

This study found 87.2 percent of beneficiaries using allowance for buying daily consuming food/clothes/transportation whereas the study carried out in Katunje, Bhaktapur Districts regarding socio- economic impact of old age allowances by Nepal government in 2008 also found 75 percent male and 82.5 percent female without source of income and using their allowance for their need and desire (Acharya, 2008).

Similarly, a study involving 8 sampled districts carried out by NPC in 2012 found majority of beneficiaries (79\%) using allowance to purchase health service and medicines. The same study also revealed the insufficiency of allowance being reported by their socio-economic background in which nearly 66 percent reported that they were satisfied with the current distribution system and nearly 10 percent reported they were not satisfied with the system. But in the researcher's study it was 51 percent using allowance for health treatment and buying medicine verses majority of them using for buying daily consuming food/clothes/ transportation. Moreover, 44.7 percent and 55.3 percent were satisfied and dissatisfied with the current distribution system with different reasons of satisfaction and dissatisfaction. But the problems reported by the beneficiaries in both studies are somehow common. In the researcher's study area beneficiaries reported to distribute allowance from the ground floor or accessible place where they do not have to climb the ladder. 
In addition, the study carried in Illam district in 2015 which was a mini research among 60 senior citizens , 25 Lepcha and 15 single women found majority of them $(86 \%)$ beneficiaries using allowance for health service, 73 percent food and 71 percent clothes. Also, the problems faced in the same study were insufficiency of the allowance money reported by 63 percent, irregular distribution of allowance (not fixed time) by 56 percent and other problems were similar like in the researcher's study (Kharel, 2015).

\section{CONCLUSION}

Though the allowance being distributed is fixed for every year, it is being distributed by bank. And for those who have problems for walking, suffering from diseases and waiting for longer period helps to rethink about reforming the programmes system such as distributing from ward or for those who have difficult in walking should be provided allowance at their door. Increasing the amount of allowance, making special facility to the disabled ones, instead of distributing allowance medicine should be provided to the beneficiaries are some of the issues explored in this study. Target people of social security allowance have been primarily using allowance money for meeting their basic personal needs for buying daily consuming food/clothes/transportation so it seems insufficient enough to sustain the target their life. Therefore, the government needs to design and implement livelihoods programs for physically capable senior citizens living below poverty line which would also use their skill and knowledge and contribute to reduce household poverty. As most of the women depend on husband, after the death of husband it is very difficult for them to support their family. Though being provided the windowed allowance, they are really in need of somehow employment so that they can at least earn for themselves to support their livelihood.

\section{REFERENCES}

Acharya, S.P. (2008). Socio economic impact of old age allowance by Nepal government: A case study of Katunje VDC, Bhaktapur district. An unpublished Master thesis, Central Department of Rural Development, Tribhuvan University.

Brown, R.J., Mitcheel, S.O., \& Kapteyn, A. (2010). Farming effects and social security claiming behaviour. WR 793 - SSA. Prepared for the Social Security Administration. 
GON (2001). Nepal interim constitution, 2007. Kathmandu: Government of Nepal.

ILO. (1942). Approaches to social security: An international survey. Geneva: ILO.

Joshi, J.C. (2010). Labour welfare administration (207 ${ }^{\text {th }}$ ed.). New Delhi: Rajat Publications.

Kirtipur Municipality (KM) (2074). Social security allowance section, 2074. Kathmandu.

Khanal, D.R. (2012). Social security/social protection in Nepal situation analysis. Nepal: ILO Country Office.

Kharel, S. (2015). The effectiveness of social security allowance program: A case of Illam district. An unpublished mini research report, Rector's Office, Research Centre, Tribhuvan University, Kirtipur.

GON (2018). Red books. Kathmandu: Ministry of finance.

NPC. (2012). An assessment of social security allowance programme in Nepal. Kathmandu: Government of Nepal, National Planning Commission.

Save the Children (2074). Information book of social security program for public, child poverty, save the children, Nepal country office. Kathmandu: Author.

Singh, S. (2013). Social security status of senior citizens in Nepal: A case study of pashupati elderly people's home. An unpublished thesis Central Department of Sociology Tribhuvan University.

Tostensen, A. (2004). Towards feasible social security system in SubSaharan Africa. Bergen : Christian Michelsen Institute.

United Nations. (UN). (2002). Madrid international plan of action of aging - 2002. Report of the Second World Assembly on Aging. Madrid 8-12 April, 2002.

United States Social Security Administration (USSSA). (2006). office of policy. Washington: Author. 